\title{
Abstracts from the 50th European Society of Human Genetics Conference: $7^{\text {th }}$ International Workshop on the History of Human Genetics
}

Copenhagen, Denmark, May 27-30, 2017

Published online: 25 April 2019

(c) European Society of Human Genetics 2019

The ESHG 2017 marks the 50th Anniversary of the first ESHG Conference which took place in Copenhagen in 1967. Additional information about the event may be found on the conference website: https://2017.eshg.org/

Sponsorship: Publication of this supplement is sponsored by the European Society of Human Genetics. All authors were asked to address any potential bias in their abstract and to declare any competing financial interests. These disclosures are listed at the end of each abstract. Contributions of up to EUR 10000 (ten thousand euros, or equivalent value in kind) per year per company are considered "modest". Contributions above EUR 10000 per year are considered "significant".

\section{Erasing borders: the British influence on human genetics in Cold War Mexico}

\section{A. Barahona}

National University of Mexico, UNAM, Evolutionary Biology, Mexico (Mexico)

After WWII human genetics was transformed from a medical backwater to an appealing medical research frontier. This talk addresses the influence of British human geneticists on the emergence of human genetics in post-war Mexico (1945-1970), emphasizing the transnational circulation of knowledge and medical practices. Radiobiology, population genetics, and cytogenetics were the first branches of human genetics that were developed in Mexico. Studies on the mutagenic effects of different emission sources of radiation, and on the distribution of genetic markers in the Mexican Mestizo and Indian population in 1950s were conducted by the group headed by physician Alfonso León de Garay at the National Commission of Nuclear Energy, who had been studied with Lionel Penrose in London, when the Galton Laboratory was the cradle of human geneticists. Cytogenetics was developed by physician Salvador Armendares who spent 2 years at the British Medical Research Council in Oxford, England under the supervision of Alan C. Stevenson, who was at the time the dean of the Council and considered one of the first physicians to work on clinical genetics. The first Unit for Research in Human Genetics in the country was launched in 1966 at the Mexican Institute of Social Security upon
Armendares' return from England. The unit contributed to exploring the effect of severe protein calorie malnutrition on chromosome structure, chromosome aberrations, Down and Turner Syndromes chromosome characterization, and the effect of mutagenic agents on chromosomes, and in the late 1970s medical problems with new methods of chromosome banding.

The genetics of prenatal diagnosis, c1950-c1990: the West of Scotland story

\section{P. Blair}

University of Glasgow, History of Medicine, Glasgow, Scotland (United Kingdom)

The 1960s was a decade of major social and cultural change, which was characterised by a decline in religious adherence and advances in many scientific disciplines. The field of genetics was amongst those where technical progress was occurring rapidly, with a key development being the advent of prenatal diagnostic testing, which enabled identification of specific genetic conditions during pregnancy. The nature of research into the detection of these conditions, enabling elective termination of affected pregnancies, raised a number of ethical issues for religious organisations and wider society to consider. This project examines how prenatal diagnostics has advanced within the social, religious and ethical background of its time, using the West of Scotland as a case-study to explore these 
issues in detail. Work in this geographical area was led by Malcolm Ferguson-Smith, who is widely regarded as one of the most eminent British medical geneticists of recent decades. Ferguson-Smith and his colleagues played a major part in the development and use of diagnostic testing techniques, including helping to establish prenatal tests for spina bifida. Ferguson-Smith was also the founder of the Duncan Guthrie Institute in Glasgow, one of the first specialised diagnostic and genetic counselling services in the UK, which made genetic services more widely accessible in the West of Scotland. This research aims to highlight the contribution of Ferguson-Smith and his colleagues and place it in a wider social context; it will utilise a variety of sources to achieve this including archival documents and oral history interviews with medical, scientific and religious figures.

\section{Margareta Mikkelsen 1923-2004: her impact as researcher and medical geneticist in Denmark}

\section{K. Brøndum-Nielsen}

Kennedy Centre, Dept. of Clinical Genetics, Rigshospitalet, University Hospital, Copenhagen (Denmark)

Margareta was born in München; and grew up in Germany. As a student in Hamburg she started in medical school. After marrying a Dane, she moved to Denmark in 1946, where she continued her medical studies, to become a medical doctor in 1955. In 1959 she joined the Institute for Human Genetics and Eugenics (Arvebiologisk Institut), which had been founded in 1938 with Tage Kemp as leader. Together with colleagues, she developed human cytogenetics, at a time when this first global analysis of the human genome had its glorious era.

She dedicated her research to Down syndrome and obtained her DMSci by a thesis on that subject. In 1970 she became a leader of the chromosome laboratory at the newly founded John F Kennedy Institute, a government research institute dedicated to research and counselling in mental retardation. Her research is internationally renowned and respected. She created a fruitful research team, being the mentor of many medical and clinical geneticists of the next generation, and establishing international collaboration. In addition to her qualities as a scientist, she was a compassionate counsellor of many families with mentally retarded children, and was engaged in societal and ethical issues such as prenatal diagnosis. She received several honors, and had many important trusted commissions, such as president of the ESHG.

As a personal witness and her student, I will review her impact on medical genetics in Denmark.
Jan Mohr and the beginning of the European Society of Human Genetics

\section{P. S. Harper}

Institute of Medical Genetics, School of Medicine, Cardiff University (United Kingdom)

The European Society of Human Genetics (ESHG) was founded on 15th March 1967, after preliminary discussions at the International Human Genetics Congress in Chicago the previous year and in Copenhagen in early 1967. Its initial meeting was held on 18-19 November 1967, also in Copenhagen, and annual meetings have been held from that time until the present, apart from years in which the International Congress of Human Genetics was also being held. The character of the Society during its early years was strongly influenced by its founding and permanent Secretary, Jan Mohr, head of the Copenhagen Institute of Medical Genetics, whose records are archived in the Tage Kemp/Jan Mohr Archive, now part of the Danish National Archives. These records show Jan Mohr's determination to keep the activities of the Society limited to the holding of an annual meeting to enhance contacts between European human geneticists, and to resist expansion to other activities. Pressures for a wider role of ESHG became irresistible in the late 1980s and a revised constitution, adopted in 1991, reshaped the Society into a more conventional and less restrictive structure. This has allowed it to play a wider and increasingly influential role in the development of human and medical genetics across Europe, with its own Journal, a range of committees covering different aspects of the field and a series of valuable reports on specific important topics.

From racial typology to population genetics? Concepts of race and the Swedish State Institute for Race Biology in Uppsala 1930-1950

\section{J. R. Kyllingstad}

Norsk Teknisk Museum (The Norwegian National Museum for Science and Technology), Oslo (Norway)

In 1935, Gunnar Dahlberg became director of the State Institute for Race Biologi in Uppsala. Under the leadership of his predecessor, Herman Lundborg, the institute had been characterized by an ideology of racial hygiene centering the idea of a superior Nordic race. Dahlberg, in contrast, was an antiracist who used scientific arguments against the ideas that his predecessor represented. He asserted that these ideas were based on a "typological" concept of race, which was 
scientifically outdated due to the rise of population genetics and the new synthesis in biology. Dahlberg was part of an influential international network of population geneticists, and contributed to an international breakthrough for scientific anti-racism by participating in drafting two statements on race, commissioned by UNESCO in the early 1950s. But neither Dahlberg nor his friends and colleagues in the US and UK rejected the concept of "race", and also under Dahlberg's management Institute continued to refer to their research as "racial biology". This paper compares Lundborg and Dahlberg's conceptualizations of race and discusses the question of continuity and discontinuity between Lundborg's and Dahlberg's approaches to the study of race and human genetic variation.

\section{Scientific, clinical and organisational development of medical genetics in Czechoslovakia from 1960 to 1970}

\section{Macek Jr., ${ }^{1}$ M. V. Simunek ${ }^{2}$}

${ }^{1}$ University Hospital Motol, 2nd Faculty of Medicine, Charles University, Dept. of Biology and Medical Genetics, Prague (Czech Republic) and ${ }^{2}$ Czech Academy of Sciences, Institute of Contemporary History, Prague (Czech Republic)

The period between 1960 and 1970 was crucial for further development of medical genetics (MG), despite the fact that the era of Lysenkoism was officially denounced in 1965 after International Genetic Congress in Brno at the centennial anniversary of Mendel's laws. MG thrived on growing clinical demands, mainly of from paediatrics (e.g. inborn errors of metabolism), internal and other medicine disciplines. The first MG department was established in 1961 at the Inst. of Child Development Res. of the former Fac. of Paediatrics and at the Biological Inst. of Fac. of General Medicine both of Charles Univ. Prague, and in 1963 at the Inst. of Paediatric Research in Brno. The Cytogenetic Soc. of Biological Soc. of the Czech Academy of Sciences was founded in 1963 . This society significantly contributed to the introduction of clinical cytogenetics, organised annual conferences with substantial participation from Western- and Eastern Europe, and thus fostered national-/international cooperation. The same role has been fulfilled in clinical-, biochemical-molecular genetics by the Society of Medical Genetics of Czech Medical Society (SLG.cz) founded in 1967. SLG was recognized as partner for the Ministry of Health (MH) to prepare the "Conception of MGs". SLG president was member of the MH Scientific board, which also issued research grant support. In 1968 the first genetic $\mathrm{PhD}$ thesis was awarded the annual $\mathrm{MH}$ prize. SLG also protected its members from political- and professional discrimination until 1989. The most important scientific achievements and publications will be presented to document the golden sixties.

Supported by 00064203 and CZ.2.16/3.1.00/24022.

\section{Risk Children. Clinical genetics, prevention and reproduction in the Federal Republic of Germany}

\section{B. Nemec}

Department for History and Ethics of Medicine, University Heidelberg, Heidelberg (Germany)

In this paper, I examine the relationship among clinical genetics, early detection, and the concepts of risk and prevention in West Germany. I am specifically interested in the early decades of the development of a human genetic dispositive of surveillance and control; the time when a comprehensive establishment of human genetic counselling centres in medical clinics, at university departments, and in private practices took place and statistic, probability calculations and a new economic logic of auto-referential financial markets shaped a profound change in the order of knowledge about the unborn child.

What was the relation between science and larger societal fields? How was a professionalization in the field of human genetic counselling shaped by specific sponsoring? How did the rapid development of clinical genetics intertwine with socio-political developments, such as that in 1976 practical consequences of cytogenetic diagnostics could be expected from the amendment to abortion law? How did nuclear research and the Contergan catastrophe change anxieties addressed to the unborn?

Important steps in these developments have already been researched in their basic structures. However, we still know very little about the role of actors on the margins of the narrower medical field and about the processes of decisionmaking. The aim of this project is to reveal this complex interrelationship that shaped the history of human genetics in the FRG, and the epistemological shift that accompanied the making of the modern "risk children".

\section{Medical genetics in Denmark: humble beginnings}

\section{S. Nørby}

Lektor Emeritus Human Genetics, University of Copenhagen, Copenhagen (Denmark)

Through its Ministry of Education, the Danish government in 1920 asked the governing body of the university of Copenhagen to evaluate the possibility of establishing a 
chair in Genetics and Racial Improvement. A crossdisciplinary committee set up by the medical and science faculties, including as a central figure the highly respected geneticist Wilhelm Johannsen (1857-1927), proposed the establishment of a chair at the medical faculty, but not until a scientifically qualified MD was available. The process was delayed by Johannsen's death in 1927, and the chair was not established until 1938 when, at the same time, a whole new building was inaugurated for the new discipline. Tage Kemp (1896-1964) became the head of the institute and in 1948 full professor of Human Genetics and Eugenics as the chair was called. During his almost 25 years as head of the Institute of Human Genetics and Eugenics Kemp managed to attract a large number of young MDs who, based on their studies of various hereditary diseases, contributed outstanding theses.

\section{German scientists at international conferences after 1945}

\section{H. I. Petermann}

Institute for Ethics, History and Theory of Medicine, WWU Muenster, Muenster (Germany)

From 1956 to 1971 four International Congresses of Human Genetics took place in Europe and USA. There were participants from all over the world, but also from Germany.

The congress president Tage Kemp of the 1st International Congress in Copenhagen (Denmark) opened the conference in 1956. At this, 12 German scientists gave talks and presented them in their native language German, like all the other participants also did. From today's view, this is as much astonishing as the topics of their presentations. For example, Gerhard Koch (Muenster) presented the results of a preliminary re-examination of the Berlin twin research series. This research was based on his work at the KWI in Berlin before 1945, which was regarded burdened.

At the 2nd International Congress in Rome 1961, the congress president Luigi Gedda said that Human Genetics had established at a field in the biological sciences. There, 23 German scientists gave different talks. In 1966 in Chicago (USA) only four German speakers gave talks at the 3rd congress. At the 4th congress, 1971 in Paris, only Widukind Lenz (Muenster) presented his research results.

After 1945, at the 1st and 2nd conference, Hans Nachtsheim und Otmar von Verschuer gave talks, both representing the continuity in research on human heredity in Germany. This meant that the scientific community did not exclude people from Germany because of political involvements.
While Human Genetics began to establish in Germany, there were less scientists at the International Conferences. Their focus was on establishing human genetics in Germany.

\section{The human genetics historical library: collecting for the future}

\section{K. Pierce}

Cardiff University, CMS, University Library Service, Cardiff, Wales (United Kingdom)

The Human Genetics Historical Library, housed in Cardiff University's Special Collections, originated in 2004 as a result of collaboration between an academic geneticist and university library staff. In order to capture the historical foundations of a science that had predominantly emerged in the twentieth century, it was recognised that there was a need to start collecting material covering the field of human genetics. As "modern" works these items would not necessarily have been identified by library staff as relevant for a "special collection"; neither are they directly related to current research interests, however by working with a specialist we are creating a collection that will have long-term historical impact, and embraces the concept of preservation for the future. Material was initially acquired because key figures in the field were passing away; alongside personal book collections donated to the library, archive material has been catalogued and housed at relevant institutions and 100 recorded interviews have taken place. The focus on human and medical genetics as a library collection is believed to be unique, but could so easily have been missed, thus emphasising the need, where possible, for library staff to work closely with academics and specialists in identifying items and topics of future importance, and to grasp opportunities where they arise. This paper will focus on collaborating, collecting, and conserving, and will discuss the historical relevance of the collection.

\section{The role of the European School of Genetic Medicine (ESGM) in facilitating the reform of ESHG}

\section{G. Romeo}

European School of Medicine, CeUB, Bertinoro (FC), Bertinoro (FC) (Italy)

In 1988, an important ESHG meeting in Cardiff started the reform of ESHG as described in two forthcoming papers (Brunner; Harper; EJHG, 2017). Not by coincidence in the same year 114 young geneticists came for the first time to 
Sestri Levante (Italy) for the week-long course in Medical Genetics, directed then by Victor McKusick (1921-2008) and myself. This year the 30th edition of the same course (made as usual of morning lectures and afternoon practical workshops) has acquired the new denomination of "Clinical Genomics and NGS". The highly-motivated faculty recruited in 1988 became the leaders of the reformed ESHG. In 1991, I was the first democratically elected ESHG President and founded the EJHG.

A few years later, the model of the Medical Genetics course was cloned into other more specific courses (Cytogenetics, Genetic Counselling, Cancer Genetics, Statistical Genetics, among others) many of which are still going on sponsored by ESHG. They became the European School of Genetic Medicine which has been attended since 1988 by more than 7000 students and has had a tremendous impact on the practice and research of medical genetics far beyond Europe, as shown by the participation of students from North Africa, the Middle East and other parts of the world.

In conclusion, ESGM not only facilitated the creation of the leadership of the reformed ESHG but also imprinted the careers of many students by giving them a unique opportunity to interact among themselves and with an excellent faculty, often leading to long-lasting scientific relationships.

\section{A landscape of women scientists: gender in early human cytogenetics in Europe}

\section{J. Santesmases}

Departamento de Ciencia, Tecnología y Sociedad, Instituto de Filosofía, CCHS, Madrid (España)

Beside the big heroes of early medical cytogenetics, the names widely recognized as the "major figures" include Joe Hin Tjio, Albert Levan, Lionel Penrose, Paul Polani, and Jerome Lejeune. At their sides at the laboratory bench and near patient bedsides were many women who participated in the investigations. They remained committed to this new biological and clinical practice-that of genetic diagnosis-and contributed to the creation of new settings and biological concepts fully focused on cytogenetic explorations. Ursula Mittwoch, Marthe Gauthier, Joy Delhanty, Patricia Jacobs and Lore Zech were among them.

What gender meant in this history goes beyond the participation of women; it includes technique: the careful handling of biological material and precision instruments. This drew upon traditional gendered practices attributed to women such as the care of the minuscule materials that belong to living beings and their needs.
This paper will present a group of women cytogeneticists from many countries to show the wide landscape in which Spanish women became involved in early cytogenetics, at a time when transnational networks were not as influential as they later became. It will show that the international connections each of them established created an environment that formed the basis upon which contemporary genetic diagnosis has been constructed in European settings.

\section{Contribution to the history of human and medical/ clinical genetics in Portugal}

\section{J. Sequeiros}

UnIGENe and Centre for Predictive and Preventive Genetics, IBMC - Institute for Molecular and Cell Biology, i3S - Instituto de Investigação e Inovação em Saúde; and ICBAS - Instituto de Ciências Biomédicas Abel Salazar, Univ. Porto, Portugal

Human genetics begins in Porto with Amândio Sampaio Tavares. In 1952, he makes an exclusion of paternity studying blood groups. In 1953, he studies sex chromatin in teratomas and undifferentiated carcinomas. In 1954, the first "sex conversion" is performed. In 1958, he begins tissue-culturing and, in 1959, performs the first human karyotype from peripheral blood, leading him to the practice of clinical genetics and genetic counselling.

Amândio Tavares influenced, among others, the paediatricians who would begin the first medical genetics services in Lisbon and Porto. Amândio Tavares, himself, never succeeded in creating a genetics service at his hospital (officially created only in 1986), but initiates his cytogenetics lab and clinical genetics service at the School of Medicine, in the same building. Currently, there are five main medical genetics services (two in Porto, two in Lisbon and one in Coimbra), for a population of about ten million. National newborn screening (PKU) begins in 1979, in Porto.

Portuguese-Spanish annual genetics conferences drove the creation of the Portuguese Society of Genetics, in 1973. The Human Genetics Society was founded in 1996. In 1979, a "competence" in clinical genetics was introduced at the Medical Association; in 1998, the medical specialty was created. The Medical Genetics College, created in 2000, starts admission by consensus, publishes a training program in 2001, and begins certifying services for the residency that would begin in 2002 (first specialists came out in 2007). In 2009, a master's course on Genetic Counselling is started in Porto (first counsellors graduated in 2011). 
Conceptions of medical genetics stipulating the role of medical genetics within Czechoslovak national health care and the role of the Czech Society of Medical Genetics in their implementation between 1970 and 1989

\section{V. Simunek}

Czech Academy of Sciences, Institute of Contemporary History, Prague (Czech Republic)

The role of medical genetics (MG) within the Czech (CZ) health-care was outlined in two "Conceptions of Medical Genetics (CMG)". The first CMG (M. Cerny; 1969) unfortunately was not realized. Therefore, the Ministry of Health $(\mathrm{MH})$ requested that the Society of Medical Genetics (SLG; www.slg.cz) prepare an updated CMG, corresponding to $\mathrm{MH}$ legal requirements, so that it could be legally enforced. The second CMG (M. Macek Sr.; MH Bulletin 1980, part 14, pp. 127-132; www.slg.cz/koncepce with English translation) integrated MG into the national health-care system. According to our knowledge the $1980 \mathrm{CMG}$ was the first in Europe to officially stipulate the role of MG in health-care, and a slightly modified CMG was later accepted for the Slovak part of federal Czechoslovakia. CMG introduced MG as a distinct medical field with special aspects related to genetic counselling (GC). It established comprehensive pre-graduate and postgraduate education in $\mathrm{MG}$, including similar curricula for genetic laboratory specialists, technicians and nurses. It outlined the major aims of MG/GC, established the hierarchical referral structure of MG departments covering all regions in order to assure equitable care, fully covered from the national health care system. Moreover, the 1980 CMG established the framework of preventive medical care, aiming at early diagnosis (e.g. of Mendelian-, chromosomal-, metabolic-, syndromic disorders), prevention (e.g. of congenital anomalies, teratogens) and treatment, including their long-term monitoring. The role of the SLG in the process of its implementation and impact on the provision of MG will be documented.

Supported by 00064203, CZ 2.16/3.1.00/24022 and SLG.

\section{Recent history of medical genetics in the German- speaking countries in the memory of contemporary witnesses}

\section{F. Söhner}

University Düsseldorf, Dept. of the History, Philosophy and Ethics of Medicine (Germany)

The presented project analyses the development of medical genetics and the establishment of its institutions in
German-speaking countries. It is designed as an oral history project including 15 to 25 actors of medical genetics from Germany, Austria and Switzerland. The focus lies primarily on-the history of science: methodical development of human and population genetics along with their consequences for medicine-institutional and political history: institutional development of medical genetics in Germanspeaking universities and health care, including regulatory, political and health-economical perspectives-social history: societal relevance and debates about medical genetics (diagnosis, methods and technologies, genetic counselling, development of attestations of paternity) and their macro ethics implications-history of ideas: new concepts of molecular genetics, increasing complexity, genome editing, synthetic biology The survey is based on methods of oral history (Obertreis 2012; Ritchie 2014). Twenty-five themefocussed, semi-structured expert interviews will provide the source material. This is supplemented by (auto-) biographical literature of protagonists of German-speaking medical genetics. Interview partners will represent German language medical genetics in its full range, i.e. include (traditionally) underrepresented groups.

The interviews will be evaluated by qualitative content analysis according to Mayring (2003) and will be used to challenge the historiography. Members of the project team are: Prof. H. Fangerau, Dr. F. Söhner, Dr. M. Krischel (all Institute of History and Ethics of Medicine, University Duesseldorf). The project is financed for two years by the German Society of Human Genetics (GFH), proposals for further funding are planned.

\section{Amândio Sampaio Tavares (1928-2016), founder of human genetics in Portugal}

\section{A. Sousa ${ }^{1,3}$;. Sequeiros ${ }^{1,2,3}$}

${ }^{1}$ UnIGENe and ${ }^{2}$ Centre for Predictive and Preventive Genetics, IBMC - Institute for Molecular and Cell Biology, i3S - Instituto de Investigação e Inovação em Saúde; and ${ }^{3}$ ICBAS - Instituto de Ciências Biomédicas Abel Salazar, Univ. Porto, Portugal

The basis for this presentation was an interview in 2008 and a question-and-answer email exchange for a tribute of the Portuguese Society of Human Genetics for his 80th birthday.

Graduated as MD (in 1952) in Porto, where he was born, he recalled that during his studies there was no proper course on genetics (only two classes, one on blood groups, and another on chromosomes and on Mendelian Inheritance). He becomes assistant professor of pathology and begins working on blood groups. 
At a bishop's request, he accomplishes the first exclusion of paternity based on ABO and Rh (1952). The following year, he performs studies of Barr chromatin in teratomas (Lancet, 1955) and publishes also on the "sex" of carcinoma cells (J Pathol Bacteriol, 1957). These prompted an invitation to a meeting on sex chromatin (London, 1957), where he first met Polani and Anders, who would become important collaborators.

In 1958, defends his $\mathrm{PhD}$ thesis on pathology of the male mammary gland; and in 1958-59 begins tissue cultures, karyotyping, and then clinical cytogenetics and genetic counselling. His many scientific interests would include, among others, statistical genetics and population genetics, medical informatics (on a Wang 2200, the first computer with a monitor in Porto), family planning, reproductive genetics, evolution, social biology and bioethics.

$\mathrm{He}$ created the first chair of Medical Genetics. He became a member of the Lisbon Academy of Sciences, and of the World Academy of Art and Science, and was the first honorary member of the Portuguese Society of Human Genetics.

\section{Witnessing genetics in the UK c.1970 to the present}

\section{T. Tansey, A. Wilkinson, A. Yabsley}

History of Modern Biomedicine Research Group School of History, Queen Mary University of London, London (United Kingdom)

' $\ldots$ the whole healthcare system is geared up to the individual... the true patient in the genetics clinic is the family...'

Professor Peter Turnpenny, Medical Genetics: Development of ethical dimensions in clinical practice and research

Human genetics has been a key topic in the work of the History of Modern Biomedicine Research Group. Our group, funded by the Wellcome Trust, studies the history of recent biomedicine, principally by employing an oral history methodology and the publication of 'Witness Seminars' (www. histmodbiomed.org). Clinical genetics has been a core theme of our Strategic Award, 'Makers of Modern Biomedicine: Testimonies and legacy' (2012-2017). The social implications of research in human, medical, and clinical, genetics, are discussed in several of our publications, for example the History of the Avon Longitudinal Study of Parents and Children (ALSPAC), c. 1980-2000 and Medical Genetics: Development of ethical dimensions in clinical practice and research. A range of textual and visual material will present samples of our work that touch on historical and contemporary debates in human genetics, such as developments in community genetics and pre-implantation genetic diagnosis. This material will demonstrate how these oral histories present significant primary historical resources to researchers and the wider public alike. The support of the Wellcome Trust is gratefully acknowledged.

\section{The establishment of genetic counselling in the twentieth century: the influence of diverse social advocacy movements}

\section{Shachar Zuckerman}

Hebrew University; Shaare Zedek Medical Center Genetics, Jerusalem (Israel)

The emergence of genetic counselling (GC) after WWII has enabled laypersons to understand and benefit from the advances made in molecular biology and cytogenetic. The subsequent developments of novel procedures in reproductive medicine expanded the scope of GC to include diagnosis and assistance in translating scientific possibilities into personal decision-making. Various social factors converged in the creation and development of GC. Foremost, the emergence of second-wave feminism, leading to the rise of the feminist health and reproductive-rights movements and its struggle for the acceptance and accessibility of birth control coupled with the decriminalisation of abortions. Other trends that also contributed to the professionalization of $\mathrm{GC}$ were the growing consumerism movement and the changing nature of medical practice: the growing attention of bioethical principles such as patient autonomy and the centrality of physician-patient relationship. During its short history, the discipline of GC has become a target of significant criticisms from various quarters. Women's reproductive rights' groups argue that GC offers a powerful means for social control, especially over women. They claim it leads to discrimination and categorization that effect woman's decision-making processes and advances a new form of eugenics. Disability rights' advocates accuse genetic counsellors of fortifying the social perception of disabled persons' lives as not worth living. Minorities' rights activists question the basic assumptions of GC regarding the integrity of individual choices and shared decision-making and demand adjusting the counselling to women from different communities. Current practices of GC worldwide are products of the aforementioned historical advancements and critical confrontations. 